\title{
What keeps science spiralling? Unravelling the critical success factors of knowledge creation in university research
}

\author{
A. Markus Travaille · Paul H. J. Hendriks
}

Received: 19 March 2008/Accepted: 2 July 2009/Published online: 14 July 2009

(C) The Author(s) 2009. This article is published with open access at Springerlink.com

\begin{abstract}
Based on Nonaka's knowledge spiral, this paper examines how processes of knowledge creation contribute to success in academia. It presents the outcomes of an indepth exploration of the workings of the knowledge spiral in a university research institute. The research shows the outstanding but undervalued importance of socialization processes. It also shows that, while research success is typically defined at the interplay of the individual, group and institutional levels, in the institute that was examined none of the four knowledge creation processes (socialization, externalization, combination and internalization) appears to run smoothly at the institutional level.
\end{abstract}

Keywords Knowledge creation - University research management . University research $\cdot$ SECI model $\cdot$ Knowledge spiral

\section{Introduction}

University research develops in what Creplet et al. (2001, p. 1530) label as an epistemic community, characterized by "the objective of knowledge creation for the sake of knowledge creation". It is true that in the academic world trends are apparent toward more commercialization and the introduction of market elements in which universities have to compete with others for research projects. These show, for instance, in calls for mode- 2 knowledge production, which involves the contention that academia is to produce knowledge not just for science's sake (mode 1), but also for the good of society in a broader sense (mode 2, Gibbons et al. 1994). These trends also surface in the related discussion of the triple helix of university-industry-government linkages and in signs of

\footnotetext{
A. M. Travaille

Institute for Molecules and Materials, Department of Solid State Physics, Radboud University

Nijmegen, Nijmegen, The Netherlands

P. H. J. Hendriks $(\bowtie)$

Institute for Management Research, Nijmegen School of Management, Radboud University Nijmegen, P.O. Box 9108, 6500 HK Nijmegen, The Netherlands

e-mail: P.Hendriks@fm.ru.nl
} 
managerialism and accountability in the management of universities (Cohen et al. 1999; Crespo and Dridi 2007). However, in spite of such trends, if university research is not to lose its identity, it is bound to remain predominantly basic research, linked in an unclear and roundabout way to the core of the universities, i.e. the educational institutes (Bleiklie 2005; Gottlieb and Keith 1997). As Jain and Triandis (1997, p. 236) put it: "Research in academia is best justified to support the institutions' primary mission of education, generating new knowledge, and service".

The fact that university research lacks a clear and undisputed purpose that is external to the research process shows the basic problem for its management, because management without a purpose is virtually impossible. It also shows that linking to the process of knowledge creation may be especially fruitful for coming to grips with both university research and its management, because the knowledge produced by science is the hallmark of the purposelessness of that activity. The assessment of what differentiates successful scientists from less successful colleagues, when that success is defined in terms of knowledge creation, provides an appealing approach for linking to management issues. The present study looks at this connection via the knowledge spiral or SECI model developed by Nonaka (Nonaka and Takeuchi 1995). The objective of this paper is to gain insight into the possibility and value of establishing meaningful connections among (a) critical success factors (CSFs) for science, (b) SECI in university research, and (c) management of university research institutes. The method used to reach this objective is a case study of the Institute of Molecules and Materials (IMM) of Radboud University Nijmegen in the Netherlands. The choice for an in-depth study via a case study approach is based on the argument that such a study of one institute allows to describe the current and desired state of the knowledge creation process of this institute.

\section{Theoretical background}

\section{Success: a driving force for scientists}

This research is set in the context of university research management. The societal embeddedness of science, which provides the overall background for university management objectives, has attracted much attention in several disciplines. Particularly the external pressures have earned a prime position on the agendas of researchers studying the identity of science related to its societal position. Academia is said to move away from what Baert and Shipman (2005, \#177, see also Enders 2005) describe as the 'Humboldtian' university, which perceives itself as an autonomous body of self-governing professionals, accountable to and monitored by itself, towards a university that, increasingly subject to market forces, has to pay explicit attention to its external accountability via audits and performance assessment. When addressing the need for and risks inherent in managing academics in a managerial sense, the discussion is mostly situated at the broad level of society, science in general or its individual disciplines. Much less systematic attention is paid to the institutional mechanisms that are to support knowledge production in old and new modes. Glances 'under the hood' of university management, scattered through the literature, also mostly address isolated elements of the management implications. For instance, Cohen et al. (1999) report that an increase in research managerial pressures, equated with managerial control, is dealt with through a re-negotiating of researchers' personal and professional interests. A prime example of such managerial pressures is the urge to publish in peer-reviewed outlets, which is shown both to encourage and discourage individual 
researchers (Hemmings et al. 2007). Ernø-Kjølhede et al. (2001) suggest that the balance between researchers' individual autonomy and managerial control may be found in a 'management for self-management' style, placing the managerial controlling task in the hands of the researchers. Determinants and differences of research group performance in the context of applied, multidisciplinary research have been identified by Harvey et al. (2002) and Landry et al. (1996). Also the connection between the management of research and education is addressed by several authors (e.g. Bleiklie 2005).

The objective of being successful in knowledge creation, so we argue, provides an appealing option when developing this research area. Not all scientists and institutes are considered equally successful in producing new knowledge. The typical—but certainly not uncontroversial-understanding of success in science refers to such categories as the quality and quantity research output, academic reputation, contribution to the discipline and society and personal development (e.g. Akerlind 2005; Whitley 2000). The success of individual scientists is related to the organization that employs them, and vice versa. The success of an institute is both a component of the individual success of scientists and an enabling condition for gaining and enhancing success (cf. Grbich 1998). Therefore, even if what defines success in science is not undisputed, that notion provides appealing hooks for studying management of science. Knowledge creation according to Nonaka: SECI, Ba and conditions for management.

Undoubtedly the most widely known model of knowledge creation is the model of a knowledge spiral developed by Nonaka and associates (e.g. Nonaka and Takeuchi 1995; Nonaka et al. 2000). Nonaka's model has had a strong impact on the field of knowledge management and basically defined the field of management of the knowledge creation process. Within the vast amount of references to this model, there is a modest, but steadily growing stream of empirical studies based on the model or testing the model (e.g. Choi and Lee 2002; Salisbury 2001). The model has also been used in the field of university-industry collaboration (Johnson and Johnston 2004; Rynes et al. 2001), but not in the area of the management of university research. The four main building blocks of the knowledge spiral model are (1) the idea of knowledge conversion between knowledge types (tacit-explicit and individual-group); (2) the recognition that knowledge creation as conversion develops within a specific context (or 'ba' in Nonaka's terminology) that may be more or less suitable for knowledge creation; (3) the notion of conditions that may help distinguish between contexts regarding their suitability and (4) the management task of providing or affecting these conditions through leadership. In our analysis, we will focus on the first three elements because element 4 most clearly resonates Nonaka's focus on an industrial environment. Below, we present the key notions of these three elements and discuss their applicability in the context of academic work situations.

\section{SECI}

The knowledge spiral model builds on the productive confrontation of two distinctions as regards knowledge, viz. tacit versus explicit knowledge, and individual versus collective knowledge. Nonaka's model is based on the conversion from tacit to explicit knowledge through interactions (see Fig. 1). First, socialization involves two or more individuals blending their mostly implicit insights to create new tacit knowledge. Joint interpretive forums (Mohrman et al. 2001) provide an example of how socialization takes place in academic settings. Second, externalization concerns writing things down, creating metaphors and analogies, modeling etc. It involves the surfacing of implicit assumptions of university researchers, for instance through cooperation with parties outside the university 


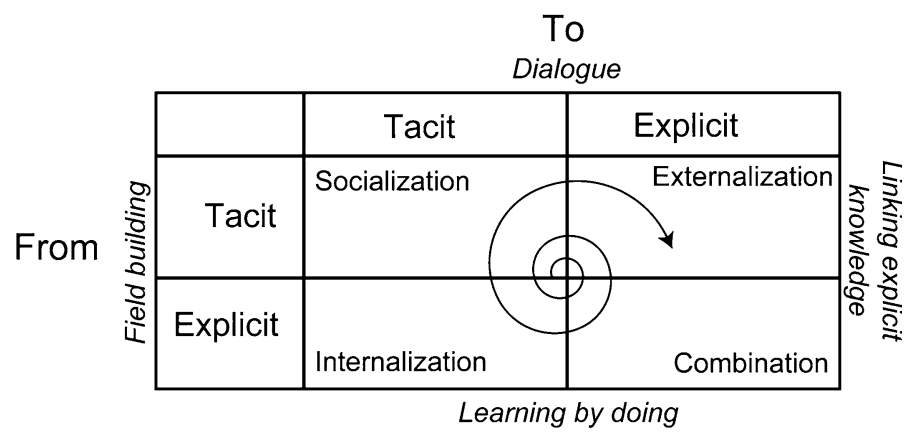

Fig. 1 Nonaka's SECI model: knowledge creation as a spiral

or in specific forms of qualitative research (Rynes et al. 2001). Third, combination amounts to sorting, adding, categorizing the new explicit knowledge in the body of existing knowledge. In university research, forms of combination include scientists citing each other's work and academia-industry cooperations (Rynes et al. 2001). Fourth, internalization refers to the creation of new tacit knowledge developed from the access to codified knowledge through learning-by-doing, goal-based training or via interpretive knowledge presentations. Involved in all four elements of SECI is a fifth element of the knowledge spiral model, which concerns Nonaka's basic notion that improved knowledge creation requires the mutual reinforcement of individual and collective knowledge. This introduces a third dimension in the scheme presented in Fig. 1 as it involves the spiral of increasing the total knowledge of an organization over time.

Nonaka's notions of knowledge conversion have not proven immune to criticism. The main criticisms can be summarized in three points. Firstly, the model is criticized for its sequential nature, moving the tacit conversions to the beginning and end of the cycle. Instead, as, for instance, Majchrzak et al. (2004) and Thomke (1998) argue, it seems more plausible to suggest that these conversions pervade all knowledge creation stages. Secondly, Nonaka is criticized for equating tacit knowledge with not-yet-explicated knowledge, thus ignoring the more fundamental understanding of tacitness in Polanyi's original analysis of the term (Cook and Brown 1999; Tsoukas 2003). A third, related criticism concerns the recognition that the model is built on a debatable understanding of what others see as the necessary tacit and collective aspects of all knowledge (Gourlay 2006; Tsoukas 2003). The notion of conversion between separate knowledge types then becomes questionable. Consequently, Nonaka has been criticized for not specifying the functional relationships between the tacit and explicit sides to individual and group knowledge (e.g. Thompson and Walsham 2004). Because these criticisms concern Nonaka's somewhat carelessly phrased epistemological standpoint, and not the basic rationale of distinguishing between aspects (and not types) of knowledge and relating these to each other (and not converting them into one another), they do not involve the submission to abandon using the model altogether. The prime value of the model, which remains unaffected, lies in its call not to ignore both the tacit and collective sides in the knowledge creation process. Its merit in focusing attention on the connections and confrontations between tacit, personal and contextualised knowledge on the one hand and explicit, declarative and supposedly universal knowledge on the other remains unaffected (Aram and Salipante 2003). Severe critics of Nonaka do not discard of his work altogether, but argue that it needs reinterpretation. Both Cook and Brown (1999) and Tsoukas (2003) reinterpret one of Nonaka's key examples, that of a bread-baking 
machine and the role of how tacit and explicit knowledge play a role in discussions between an engineer and a baker. Their analysis is meant to show that while specific elaborations are flawed, at the same time Nonaka's core notions concerning the role of individual and collective tacit knowledge in knowledge creation remain unaffected. As Cook and Brown (1999, p. 394) argue, the criticisms leading to reinterpret elements of Nonaka's theory 'serve to strengthen Nonaka and Takeuchi's central claims about knowledge creation'.

The distinctions between tacit-explicit and individual-group knowledge have also been embraced, in similar or related terminology, in the sociology and economics of science. For instance, Polanyi (1966), on whose work Nonaka's main distinction between tacit and explicit knowledge is based, develops his notions of tacit knowing to overcome what he considers misguided dichotomies between sciences and humanities. Polanyi's aim is to highlight that all scientific knowledge is based on personal knowing-participation through indwelling. The primordial status of explicit knowledge (books, articles, results of experiments etc.) in science-at least in the Western interpretations of science-is also put in perspective by the recognition of how scientific laboratory work heavily depends on tacit aspects of knowing (Knorr-Cetina 1999; Latour et al. 1979). The standard notion-or myth - of the isolated individual scientist as the prime knowledge carrier in academia is subject to qualification because of the broadly recognized relevance of the aforementioned epistemic communities in science, the role of laboratories in academic knowledge production (Knorr-Cetina 1999) and Thomas Kuhn's notion of paradigms. The definitions of these concepts draw heavily from an understanding that knowledge and knowing are both tacit and collective. The associated discussions clearly connect to Nonaka's approach. It is safe to assume therefore that the notion of confronting tacit and explicit knowledge in individual and group settings is meaningful in the context of the present study, and not restricted to industry settings.

\section{The concept of $B a$}

Because of the problems involved in directly manipulating knowledge creation, Nonaka does not connect management - the task of furthering the spiral-directly to the individual stages but to their conditions. Knowledge creation takes place in a (physical and mental) environment identified by Nonaka as ' $b a$ ', or the 'shared context in which knowledge is shared, created and utilized' (Nonaka et al. 2000, p. 14). Many different $b a$ 's are likely to exist in any organization, including in science as an organization and universities as science organizations. For instance, in a university research institute two different $b a$ 's are defined by a group of researchers and the institute itself. These two contexts are evident when looking at the daily environment in which scientists work in an institute. Most of the research is performed in the context of the group. The other $b a$ is the research institute itself, which, in the case study presented below, concerns an interdisciplinary research institute that was deliberately established for the purpose of cross-pollination among different disciplines. In this respect such an institute, and the $b a$ it produces, constitutes a very different 'knowledge creation company' than the traditional disciplinary universityresearch institutes. Many other $b a$ 's may be relevant as well. Most groups, for example, have small sub-groups that work together on a specific topic, with their own specific $b a$. Another $b a$ is the collaboration between scientists from different institutes who can be physically separated by thousands of miles. Usually experts on specific fields do not work in the same (physical) environment but they do have a shared context. They meet each other in conferences, workshops and via e-mail, they publish in specialized journals and their collaboration is sometimes formally recognized as a network by a funding agency. 
Enabling factors for knowledge creation

In Nonaka's model the concept of $b a$ is the linking pin between knowledge creation and its management. According to Nonaka's model, management of knowledge creation involves finding, building and connecting all relevant $b a$ 's. Nonaka and Takeuchi (1995, pp. 73 ff.) discuss five enabling factors.

- Intention, defined as the individual's or organization's aspiration to its goals. The relevance of this enabling factor to academic endeavors becomes evident, for instance, in the distinction between mode-1 and mode-2 knowledge production (Gibbons et al. 1994), which links to the purpose, utility or relevance of science. The heated debates on this distinction reinforce the significance of Nonaka's first enabling factor, as well as the problematic, contested process of defining what intentions are or should be in the case of university research.

- Autonomy, which is related to independency. As mentioned earlier in this paper, the relevance of this enabling factor for discussions of science as social activity is recognized by many authors (e.g. Lambright and Teich 1981). It is perhaps among the most debated elements of science as social institution, partly because of the image of the scientist as a free, somewhat isolated, and thus autonomous ivory tower inhabitant. Issues of autonomy play a key role in the debates around mode- 1 and mode- 2 knowledge production, where they are usually treated as more visibly associated with mode-1 and threatened by mode 2 (Henkel 2005; Nowotny et al. 2003).

- Fluctuation and creative chaos, or an intentional disorder in an organization or in processes. The generic nature of this enabling factor implies that its relevance to science is hardly problematic. It may apply to any creative work, whether carried out by individuals or groups.

- Redundancy, which is defined as the intentional overlap between experience and knowledge that is necessary for mutual understanding. The notion of transdisciplinarity, that is one of the main driving forces behind the call for a mode- 2 knowledge production, may be threatened by a lack of redundancy (different disciplines need to be able to exchange their worldviews and conceptual schemata to start cooperations).

- Requisite variety, which is the internal diversity needed to deal with the variety imposed by the environment of the organization. In the setting of university research, what the environment is and which variety needs it imposes, depends on the level of analysis. At the level of science as a whole, society and public administration are relevant elements of the environment. Requisite variety then, for example, relates to how needs of accountability and recognition (imposed variety) are to be met by delivering variations of research (internal diversity). At the level of a university or research groups, other elements of the 'building of science' form part of the environment. Requisite variety at this level refers, for instance, to the mix of competencies (internal diversity) needed to produce the types of contributions that will get accepted by journals (imposed variety).

\section{Research methods and case description}

The purpose of the research presented in this paper is to surface the CSFs of knowledge creation in a specific university research institute, the Institute for Molecules and Materials (IMM). The case organization and the methods used in the research are described below. 
The institute for molecules and materials (IMM)

The institute for molecules and materials (IMM) is one of 22 research institutes at Radboud University Nijmegen, which is a medium-sized research university in The Netherlands. Established in 1923, Radboud University has nine faculties and enrolls over 18.000 students in more than 100 study programs. Currently, about $10 \%$ of its students come from countries outside The Netherlands. The university has an academic staff of 2,250 FTE, on a total of 4,300 FTE. IMM is the largest research institute at the Faculty of Science of Radboud University Nijmegen. It is internationally renowned in its field. In the most recent national research assessment (2008), IMM has scored an average of 4.5 on the criteria of quality, productivity, relevance and viability $(4=$ very good, national leading, $5=$ excellent, international leading, see VSNU 2003). Twenty-one research groups are associated with the institute originating from both chemistry and physics. The IMM's main research activities, as represented by the research themes of 'Correlated Systems', 'Self-Organizing Systems', and 'Biomolecular Systems', will remain the same for the next years. Certain forces are currently urging the institute away from disciplinary research towards interdisciplinary research. These forces push the institute towards a transition from a federation of discipline-based groups with little formal management 'power' to an interdisciplinary institute where the individual disciplines are sustaining the overall research institute. Recently, more funding was attracted for interdisciplinary research on nanomaterials and biomolecular systems. Both areas require a strong collaboration between the existing groups for the institute to become a successful player in these strongly competing and highly fashionable fields.

In 2008, the total IMM staff was 225 FTE, including 170 FTE scientific and 55 FTE support staff. Some $30 \%$ of the scientific staff held permanent appointments, with an additional $45 \% \mathrm{PhD}$ students and $25 \%$ post-docs employed on a temporary basis. Approximately $41 \%$ of funds for the scientific staff are provided directly by the government for research and education (so-called "eerste geldstroom"). Additionally, 27\% of the scientific staff are paid from funds received in competition from national and international science foundations (NWO, KNAW, STW; so-called "tweede geldstroom"). The remaining $32 \%$ is accounted for by contract funding for specific research projects financed by third parties, including EU-frameworks and funds provided by industry (so-called "derde geldstroom"). Funding of the individual research groups is mostly obtained via short-term and long-term research projects, financed by research funds ("tweede geldstroom") and contract funding ("derde geldstroom"). For these projects PhD students are appointed for 4 years and post-docs for one to 4 years. The university finances most of the tenured staff. The total number of publications in the year 2008 was some 300 articles in scientific journals (including Nature and Science) and 35 dissertations. Furthermore, the institute produced several professional publications (books, etc.) and patents. The IMM has formed cooperations with research labs of all large multinationals in the Netherlands and with national research institutes. The IMM also collaborates with international research institutes and universities. Several professors are temporarily employed at other universities. The IMM is the birthplace of a dozen highly successful commercial spin-offs.

The IMM's structure is such that there are three 'natural' levels to be investigated, viz. the level of the individual, the group and the institute. As regards the individuals, four functions can be distinguished that are described below.

- The group leaders, who are usually professors, are responsible for the group. They are the budget holders and are authorized to contract people. Their responsibilities include the management of their group and educational tasks in the science faculty. 
- The staff members are scientists with permanent positions. They usually have a $\mathrm{PhD}$ degree. They are responsible for projects within the group. In most cases, they are the daily supervisors of post-docs and $\mathrm{PhD}$ students. Compared to group leaders, staff members are more involved in scientific details and less in management tasks. They also have an educational task. Their function is important with respect to the continuity of knowledge in a group.

- The scientists that are temporarily employed are post-docs and PhD students. They are the principal producers of knowledge. The knowledge they produce is mostly written down in papers, a thesis or presentations. The fact that they are temporarily employed means that their specific knowledge is lost when they leave the group. $\mathrm{PhD}$ students usually have a (small) educational task.

- The technicians, who all have an engineering background, also hold permanent positions in the group. Their main task is to provide scientists with state-of-the-art equipment. They must have the skills to operate and build that equipment themselves. They have an important function with respect to the continuity of technical skills and know-how.

\section{Sampling method}

Data in the research were collected via a sample of in-depth interviews. The sampling in the research qualifies as 'stratified purposeful, saturation-driven sampling', which fits well within the qualitative nature of the research (e.g. Patton 2001). The interviewees were selected as a stratified sample, with the strata defined such that the four functions (group leaders, staff members, temporary researchers, technicians) would be represented. Candidates were selected randomly per category, provided they were employed by the institute for 2 years or longer and for more than 2 days a week. These criteria add elements of purposive sampling to the procedure, aimed at ensuring the inclusion of well-informed cases. The stop criterion for a new round of interviews was whether 'saturation' of data had been reached. The approach of looking for data saturation, or using the information richness of the data as a guiding principle for setting the sample size, is a received principle of sampling in qualitative research (Patton 2001). Saturation refers to the emergence of relevant categories of the researched phenomenon, viz. the CSFs for SECI in university research as stepping stones for university research management. The procedure followed was such that, starting at the third round of interviews, an evaluation was made after every new round to assess if new insights had become available during the last interviews. This procedure led to interviews being held with three group leaders, four staff members, six temporarily employed scientists and four technicians. The high degree of homogeneity as regards the accepted definition of successful scientists in physics and chemistry as mature fields of science lends support to the adequacy of the present sample size, also given the explorative nature of the research (cf. also Patton 2001).

\section{Interviews}

The purpose of the interviews was to assess research work in academia in general. To ensure this focus in the interviews, respondents were asked to concentrate on issues that were independent from the context of the individual organization. While the local infrastructure and environment differs per university research institute, their overall circumstances are comparable. 
The interviews were organized in three parts. The first part of the interview was focused on what it takes for a scientist (or technician) to be successful. Respondents were asked to identify the three most important individual success factors. They were also asked, by means of a similar approach, to identify the three most CSFs for their group and the IMM, leading to nine success factors, three for individuals, the group and the IMM. In the second part respondents were asked to describe the relations between the identified factors in order to shed light on how CSFs of individuals are related to the CSFs of the group or the IMM and vice versa. The last part of the interview focused on the process of becoming successful and the relations between the knowledge creation process and their success. The respondents were asked to describe whether their CSFs were being met or not. If they considered themselves, their group or the IMM successful, they were asked how they thought this was achieved and what role the knowledge creation process played in the success. If they considered themselves, the group or the IMM not to be successful or not sufficiently successful they were asked to give their opinion on how to become successful/more successful.

\section{Results}

The presentation of the results given below follows the structure of the interviews. First, we will present and discuss the CSFs mentioned by the respondents as elements of $b a$ (first two parts of the interviews). Next, we will address the connection of these CSFs to the stages of the SECI model (third part of the interviews, assessment of current situation). Finally, the management implications as drawn by the respondents will be discussed (third part of the interviews, assessment of desired situation, gap analysis and management implications).

Critical success factors and enabling conditions

Table 1 shows the CSFs the respondents mentioned. To assure that no purely individual motives would be used in the analysis, only those success factors were processed that were brought up more than once. If respondents used different words for the same concepts, their answers were grouped using the most common term. If terms were considered closely related but not identical, both terms were kept but grouped in the same box (e.g. synergy/ coherence). The success factors have been ordered into four categories that fit the knowledge perspective adopted in this research.

- Knowledge: those success factors that refer to the scientific and technical knowledge that feeds into the knowledge creation process. For example, a materials scientist needs other know-how and equipment than a biologist.

- Knowledge carrier: those success factors that are related to talents and characteristics of the knowledge carriers at the three levels of analysis (individuals, teams, institute). Examples are perseverance and ambition of individuals and group composition of teams, the skills needed for collaboration with other knowledge carriers (individuals, groups, institutes), including communication and presentation skills needed for individuals to engage in teamwork and individual and group competencies required for cooperations between teams.

- Manifestations of knowledge: those success factors that concern the manifestations of the produced knowledge. In the scientific community these are usually translated into published papers, citation indices, granted proposals, being invited to (international) conferences etc. 
Table 1 Critical success factors for individuals, groups and the IMM

\begin{tabular}{|c|c|c|c|}
\hline & Individual & Group & IMM \\
\hline Knowledge & $\begin{array}{l}\text { Know-how }(11 \times) \\
\text { Creativity }(5 \times) \\
\text { Insight }(2 \times)\end{array}$ & - & $\begin{array}{l}\text { Interdisciplinary } \\
\quad \text { research }(3 \times) \\
\text { Scientific quality }(2 \times) \\
\text { New research }(2 \times)\end{array}$ \\
\hline Knowledge carrier & $\begin{array}{l}\text { Passion }(4 \times) \\
\text { Perseverance }(3 \times) \\
\text { Autonomy }(3 \times) \\
\text { Curiosity }(2 \times) \\
\text { Initiative }(2 \times) \\
\text { Communication } \\
\quad(4 \times)\end{array}$ & $\begin{array}{l}\text { Collaboration }(4 \times) \\
\text { Group atmosphere }(3 \times) \\
\text { Interactions }(2 \times) \\
\text { Group size }(2 \times)\end{array}$ & $\begin{array}{l}\text { Collaboration }(9 \times) \\
\text { Communication }(2 \times)\end{array}$ \\
\hline Manifestations of knowledge & - & $\begin{array}{l}\text { Education }(4 \times) \\
\text { Publications }(3 \times) \\
\text { Output }(2 \times) \\
\text { Granted proposals }(2 \times)\end{array}$ & Output $(3 \times)$ \\
\hline $\begin{array}{l}\text { Management context of } \\
\text { knowledge }\end{array}$ & - & $\begin{array}{l}\text { Funding }(4 \times) \\
\text { Reputation }(3 \times) \\
\text { Strategy/Original approach } \\
\quad(2 \times) \\
\text { Good group leader }(2 \times) \\
\text { Infrastructure }(2 \times)\end{array}$ & $\begin{array}{l}\text { Reputation }(7 \times) \\
\text { Mission statement }(4 \times) \\
\text { Synergy/Coherence }(3 \times)\end{array}$ \\
\hline
\end{tabular}

The figures between brackets show the number of people that have mentioned this success factor

- Management context of knowledge: success factors that concern the adequacy of regulation at all possible levels and for all possible subjects. For instance, it includes management defined as the responsibility for the entire institute, supervision of students, or the self-management of an individual scientist. It includes all factors necessary for adequately performing the different management functions, such as the skills of managers, their sphere of influence and the roles they play in an organization.

Table 1 shows that individual scientists and technicians consider themselves successful when they have sufficient know-how and creativity. Their communication skills are most relevant to collaborations and interactions with others (mostly in the group). A passion for science combined with sufficient perseverance, curiosity and initiative in an environment where they have certain autonomy is needed to achieve their targets.

A scientific group is successful when there is sufficient output (publications, granted proposals and education). A good group atmosphere combined with the proper infrastructure, money and a good reputation helps to realize this output. The qualities of the group leader are important for the success of the group, as this person is mostly responsible for the group management and usually determines its long-term strategy. Among these qualities, his or her reputation as an academic proved to be of paramount importance.

The research institute is considered successful when it carries out and stimulates interdisciplinary and new high-quality research. This research should lead to publications in high-impact journals. To reach these targets collaboration and adequate communication within the institute are required. To enhance the collaboration and communication, a welldefined and recognizable mission statement and the synergy resulting from such a mission statement are required in order to create an institute with a significant reputation.

An important element in analysing the CSFs involves identifying and interpreting if and how Nonaka's five enabling conditions emerge by means of these CSFs, as these enabling 
conditions provide the hooks for managing knowledge creation. The first enabling condition, intention, is related to the passion, initiative and perseverance of the individual and to the strategy of the group/group leader and the mission statement of the institute. Autonomy, the second enabling condition, is related to the know-how of the individual and the funding and infrastructure of the group and the institute. Most respondents indicated that they only support the development of new research and/or interdisciplinary research when engaging in the associated efforts was their own decision. The third enabling condition, fluctuation and creative chaos, is related to creativity and curiosity and to interactions and collaboration in the group and in the institute. A good group atmosphere and an appropriate group size stimulate creative chaos. Fourthly, redundancy is related to a common background, or collective knowledge, which is needed to be able to communicate and is usually complementary in nature. Communication between individuals in the institute is only possible when redundancy is present. The synergy and coherence of the institute increase redundancy. Requisite variety, the fifth enabling condition, marks the border where too much synergy does not lead to new knowledge. This is the basis for the existence of different groups with different expertise in the institute.

These results show how the enabling factors materialize in the collected CSFs. They also show that the CSFs in the output category are not explicitly linked to enabling conditions. Apparently the output itself is not an enabling factor for creating new knowledge. A successful output, however, is indirectly related to the success of the knowledge creation process by stimulating the realization of other enabling conditions.

\section{Knowledge creation process}

The results from the first two parts of the interviews (identifying CSFs and establishing the relationships among them) were used to identify the role of knowledge creation in the success of individuals, groups and the institute. In the third part of the interview, to link the CSFs and enabling factors to SECI, respondents were asked how well they had succeeded as regards each of their success factors. When respondents felt that their success factors were realized they were asked how this was done. This resulted in a series of 'best practices' that were analyzed in the context of the SECI model and related to one of the SECI processes. Table 2 shows the outcomes of this part of the interviews. If the targets that were set were not met, the respondents were asked how they thought the target could be met. This led to the series of suggestions for improvements presented in Table 3 . These will be discussed below.

Table 2 shows that most of the successful SECI processes in the IMM take place within the context of the group and the individual. The institute itself appears not to play a very large role as yet in the knowledge creating process. Especially in the combination and internalization part the institute plays almost no role at all.

The findings give a strong indication of the importance and status of socialization and externalization. The generation of output is a key indicator of success. However, the data also show how important socialization is. Furthermore, the processes of writing papers/ proposals and providing education were often mentioned in discussions of the CSFs, but they do not explicitly show up in connection with knowledge creation. The externalization process is considered important in the recognition of 'successful scientists'. Therefore, success is related to output, but a scientist who is asked when the 'new' knowledge was created mostly points out a socialization-related process (cf. Grbich 1998). This also signals that not the externalization process itself is considered crucial in academia, but its result, viz. the output as a manifestation of knowledge. This finding is in line with the 
Table 2 SECI components already implemented for individuals, groups and the IMM

\begin{tabular}{|c|c|c|c|}
\hline & Individual & Group & IMM \\
\hline Socialization & $\begin{array}{l}\text { Discussions/feedback/ } \\
\quad \text { interactions/brainstorming } \\
\quad(11 \times) \\
\text { Working with expert }(8 \times) \\
\text { Collaboration }(6 \times) \\
\text { Group meetings }(3 \times) \\
\text { Project meetings }(2 \times)\end{array}$ & $\begin{array}{l}\text { Group meetings }(11 \times) \\
\text { Collaboration }(4 \times) \\
\text { Discussion/Feedback/Sharing } \\
\quad \text { expertise }(4 \times) \\
\text { Group atmosphere/Social } \\
\quad \text { rules }(3 \times) \\
\text { Social events }(3 \times) \\
\text { Small group size }(2 \times) \\
\text { Coherence of topics }(2 \times)\end{array}$ & $\begin{array}{l}\text { Interdisciplinary } \\
\quad \text { research }(3 \times) \\
\text { Scientific quality }(2 \times) \\
\text { New research }(2 \times)\end{array}$ \\
\hline Externalization & $\begin{array}{l}\text { Group meetings }(4 \times) \\
\text { Sharing of results }(3 \times) \\
\text { Collaboration }(2 \times)(\text { writing } \\
\quad \text { papers) } \\
\text { Project meetings }(2 \times) \\
\text { Teaching }(2 \times) \\
\text { Express clear technical demands } \\
\quad(2 \times)\end{array}$ & $\begin{array}{l}\text { Group meetings }(9 \times) \\
\text { Collaboration }(3 \times) \\
\text { Supervision from staff }(3 \times) \\
\text { Sharing results/Conferences } \\
\quad(2 \times) \\
\text { Discussion about research } \\
\quad \text { strategy }(2 \times)\end{array}$ & $\begin{array}{l}\text { Thematic afternoons } \\
\quad(4 \times) \\
\text { Symposia }(2 \times) \\
\text { IMM courses }(2 \times)\end{array}$ \\
\hline Combination & $\begin{array}{l}\text { Collaboration }(4 \times)(\text { Combining } \\
\quad \text { expertise) } \\
\text { Project meetings }(2 \times) \\
\text { Combine results }(2 \times) \\
\text { Helping PhD students }(2 \times)\end{array}$ & $\begin{array}{l}\text { Group meetings }(4 \times) \\
\text { Group of people with different } \\
\quad \text { background }(2 \times)\end{array}$ & $\begin{array}{l}\text { Collaboration } \\
\text { between groups } \\
(2 \times)\end{array}$ \\
\hline Internalization & $\begin{array}{l}\text { Learn things you have to know } \\
(6 \times) \\
\text { Build up know-how to work } \\
\text { autonomously }(4 \times) \\
\text { Reading papers and surfing } \\
\text { internet }(2 \times)\end{array}$ & - & - \\
\hline
\end{tabular}

assessment made by Rynes et al. (2001) that few instances of both socialization and externalization are visible in the academic community, as top journals hardly publish personal reflections by academics (externalization) or deep-delving inquisitions of competitors' assumptions.

We found that the combination process is often connected to the application of knowledge. The results of the interviews indicate that most of the new knowledge that is created is highly specialized knowledge. It can therefore only be understood by a small group of people and is only of value to that group. These are the people that work in the sub-group on the same subject and/or the experts working in the same field throughout the world. These are two environments in which knowledge is created by combination, but this is done outside the context of the group or the research institute. Therefore, the combination process within the $b a$ of the institute is not of major importance in the generation of new knowledge. Consequently, the combination process develops mainly outside the direct sphere of influence of research institutes. It is usually an issue in which scientists operate autonomously without any interference from the institute.

The call for multi-disciplinary research, as apparent in the investigated institute and elsewhere, is at odds with this finding, as it puts the process of combining knowledge in different fields in the center of management attention. Obviously, an interdisciplinary research institute can play an important role in these combination processes by providing the means and assets to create a common background. This means that the establishment of interdisciplinary research institutes requires a change in the management attitude since 
Table 3 Outcomes of gap analysis: SECI components desired by individuals, groups and the IMM

\begin{tabular}{|c|c|c|c|}
\hline & Individual & Group & IMM \\
\hline Socialization & $\begin{array}{l}\text { Collaboration } \\
\text { with people } \\
\text { from other } \\
\text { group }(2 \times)\end{array}$ & $\begin{array}{l}\text { More interactive } \\
\text { group meetings } \\
(5 \times) \\
\text { Management of } \\
\text { technicians }(2 \times) \\
\text { More interactions/ } \\
\text { collaboration in } \\
\text { lab }(2 \times)\end{array}$ & $\begin{array}{l}\text { Social activities }(7 \times) \text { (internal network) } \\
\text { Open lab days/visits }(6 \times) \\
\text { Interdisciplinary research/collaboration }(5 \times) \\
\text { More coherence of topics/mission statement } \\
\quad(4 \times) \\
\text { Better symposium }(4 \times) \text { (more interactive) } \\
\text { More interactions between PhD students }(3 \times) \\
\text { More interactions between group leaders }(3 \times) \\
\text { Visible support from group leaders for IMM } \\
\quad(2 \times) \\
\text { Meetings and information exchange more } \\
\text { obligatory }(2 \times) \\
\text { Better communication top down }(2 \times) \\
\text { Sharing of expertise/setup }(2 \times) \\
\text { More courses }(2 \times) \\
\text { Better information }(2 \times)(\text { annual report, website) }\end{array}$ \\
\hline Externalization & - & $\begin{array}{l}\text { More emphasis on } \\
\text { problems/ } \\
\text { questions }(4 \times) \\
\text { More interactive } \\
\text { group meetings } \\
(3 \times)\end{array}$ & $\begin{array}{l}\text { More information }(8 \times) \text { (who knows what) } \\
\text { Lab visits }(4 \times) \\
\text { Better symposium }(4 \times) \\
\text { Better courses }(4 \times) \text { (program and coordination) } \\
\text { Better website }(4 \times) \text { (expertise list) } \\
\text { Annual reports }(3 \times) \\
\text { Create IMM masters }(3 \times) \text { (students in more } \\
\text { than one lab) } \\
\text { More uniform presentation (logo, publications } \\
\text { etc.) } \\
\text { Emphasize collaborations }(2 \times) \\
\text { Group policy }<->\text { mission statement }(2 \times) \\
\text { More }(\text { IMM-related) interdisciplinary research } \\
\quad(2 \times)\end{array}$ \\
\hline Combination & - & - & $\begin{array}{l}\text { Combination of expertise/experiments in other } \\
\text { groups }(3 \times) \\
\text { Proposals for interdisciplinary projects }(2 \times)\end{array}$ \\
\hline Internalization & - & - & - \\
\hline
\end{tabular}

specific assets have to be provided to stimulate the combination of background knowledge to create sufficient redundancy in the institute. This tension between the current situation in which combination lies outside the 'natural' realm of interest within a university research institute and the explicit attention for combination implied in the aspiration to increased interdisciplinarity may at least partly explain the problems universities face in achieving that aspiration.

Table 2 shows that the internalization process is not mentioned frequently. This is in accordance with Argyris' (1996) claim that the scholarly community pays little visible attention to internalization. It is still remarkable, because know-how, which mostly develops through internalization, emerges from the interviews as one of the most important success factors. An explanation for the relative lack of attention for internalization is that most scientists may consider it evident that they update their know-how regularly. Another element of explanation may be that the knowledge to be updated is the same highly specialized knowledge mentioned above. Scientists usually acquire this knowledge outside the context of their group or the institute, which also moves the internalization process somewhat outside the direct focus of attention of that institute. 
Management implications

Table 3 shows the desired improvements on the knowledge management categorized in the different SECI processes. These results were obtained in the same way as described in the previous section but in these cases they correspond to success factors that were not yet being met. The most obvious result from Table 3 is that more interactions are desired, both at the group level and at the institute level. Although many of the improvements are already partly implemented, they can be improved by increasing the interaction or communication, for example, at the group meetings, which by most respondents were considered important for the exchange of knowledge. However, most respondents argue that they do not have the necessary background knowledge to have a real interactive discussion during these meetings. This is caused by the detailed level of discussion and by the fact that most group members are active in different research areas. Both phenomena are related to a lack of common background. The resulting lack of interaction usually decreases when a groups shows a larger degree of coherence between its research topics. However, the danger of a homogeneous, cohesive group is the lack of fresh opinions that might provide eye-openers or solutions to existing problems. This illustrates the problem of achieving the right balance between requisite variety and redundancy as enabling factors of the SECI process. The example of group meetings clearly shows the problems of the research institute when organizing meetings and discussions. All the aspects mentioned for the group meetings present even larger problems to meetings with the entire institute.

Most respondents agree that interdisciplinary research (here mostly between physics and chemistry) opens opportunities for new, high-quality research. Most respondents also agree that dedicated resources ( $\mathrm{PhD}$ positions, post-docs) for interdisciplinary research are the best option to stimulate this kind of work. The most difficult issue, however, is to identify where successful collaborations can be started. Usually, multiple failed attempts precede a successful cooperation. It became clear during the interviews that most respondents, particularly the temporarily employed scientists, experienced a lack of information concerning the current know-how and expertise of individuals and groups in the institute. A possible solution would be to define the role of a knowledge broker or 'rainmaker'.

Another problem of the research institute is the lack of a common social background. The group is a strong social entity as labs, offices and coffee rooms are shared among the members of a group. The IMM, on the other hand, has almost no such activities although many of the staff would like to see more of such activities organized. Apparently it is important to know each other personally before collaboration is established.

The discussion about the context in which the internalization and combination parts take place is supported by the results in Table 3. In the case of the IMM, practically no suggestions as to how to improve these factors were made in the group and institute contexts. We argue that this is largely due to the fact that the $b a$ of these processes is not closely related to the group or the institute, but to a scientific environment that mainly exists separately from both.

The topics discussed above clearly illustrate the importance of socialization in the SECI model. The change in the funding system of research, however, has forced scientists to externalize more of their knowledge for reasons of accountability and comparability. It is beyond question that the change of funding policy has increased the importance of the externalization process and has led to more output, but whether the quality of that output is as high as it would have been without the pressure of externalization remains a debatable question (e.g. Baert and Shipman 2005; Dewett and Denisi 2004). 


\section{Conclusion}

The research presented in this paper shows that the CSFs for being a successful scientific institute become particularly meaningful when related to the enabling factors for the four contributing SECI processes, because they allow sorting these processes according to their relative importance. On the basis of this research it can be argued that universities should distinguish between two groups, firstly, the processes of socialization and externalization and secondly, those of combination and internalization.

As regards socialization and externalization the research confirms the primordial importance of explicit knowledge, as the outcome of the externalization process. In the case organization-which in this respect is probably typical of a western university research institute- externalized knowledge appears as the key to success. However, the results also yield two additional insights. Firstly, they show that not the process of externalization is considered the touchstone of success, but its outcome. The very existence and persistence of epistemic communities depends on the circulation of knowledge that is made explicit but not codified "since it remains mainly internal to the community" (Creplet et al. 2001, p. 1530). Secondly, the findings confirm the significance of tacit-knowledge exchange for knowledgeintensive work, including R\&D and basic research. For the generation of explicit knowledge, the socialization process is considered fundamentally important. The recognized importance of tacit knowledge appears to depend on the number of people involved. When individuals work alone or in small groups, tacit knowledge is considered particularly important. It takes years to build up the skills and experience needed for publishing. It is this experience and the associated skills that are highly appreciated for establishing cooperations. However, in large groups - and certainly at the scale of a research institute - evaluating the skills and experiences of all potential cooperation partners is next to impossible. In this case not cooperations, but performance and accountability are at the center of attention as touchstones for funding and time allocation, as assessed on the basis of a researcher's production of explicit knowledge. These perspectives put the socialization processes on the back benches of management attention, relevant only in an indirect way as possible facilitators of explication processes. The $b a$ in which knowledge is created affects its relevance. If the primary task of a research institute is to provide society with applicable knowledge, the generation of explicit knowledge will be most valuable. However, gaining access to networks and delivering highly educated people put a strong emphasis on the creation of tacit knowledge. The indispensable basis of a university's research policy is therefore the definition of the research institute's primary target that should provide the criteria for deciding whether and how to influence the knowledge creation process. External goal-setting should be addressed in conjunction with the $b a$ or $b a$ 's the university should engage in to achieve the goals. Without an explicit consideration of these $b a$ 's, a meaningful connection to the knowledge production process and its management is hard to conceive.

The other two SECI processes, combination and internalization, appear to play a different, perhaps less dominant, yet more difficult role in the realization of academic success and as triggers for management action. While the particular value of the combination process gets recognized in a broader context, for instance, for bringing new knowledge into an organization (Creplet et al. 2001), this research suggests that in university research the combination process is mostly of importance to the generation of background knowledge and redundancy. Research institutes and, to a lesser extent, research groups, do not play a significant role in the combination of 'new' knowledge. Networks and collaborations with specialists worldwide are of greater importance here. The socialization and externalization processes, on the one hand, and the combination process, on the other, appear to develop at different levels. The risk involved is 
that the combination process may prove the missing link in the overall knowledge spiral at the organizational level. The principal enabler of the process of combination is redundancy. A lack of redundancy drastically lowers the efficiency of knowledge creation. A prime objective for management, particularly in the case of interdisciplinary research, is therefore to enhance redundancy within research environments, for instance, by increasing the mutual interactions and selecting coherent research topics. The pleas for mode- 2 knowledge production, with its emphasis on multi-disciplinarity and applied research, may be interpreted as calls to put the combination process on the front row. What this research suggests is that indeed combination appears as a crucial yet problematic process for universities establishing and maintaining their knowledge spirals. Because of the different level at which it develops as compared to the socialization and externalization processes it may be wiser not to treat combination as the core element in a separate knowledge production mode. For universities - and societies - it would be advisable to invest in merging elements of mode-2 into mode-1, and not in developing a separate mode-3 (cf. Huff and Huff 2001) aimed at avoiding the drawbacks of modes 1 and 2.

As far as knowledge internalisation is concerned, the main risk may be that this process is mostly seen as an individual responsibility, fitting within the prevailing perception of science as the primary realm of the solitary explorer. Just like combination, internalization is indispensable to sustain a knowledge spiral. What is perhaps most striking in the case study of the IMM is not which CSFs were linked to this process, but the fact that respondents did not seem to consider organizational entities highly influential as regards internalization (see Tables 2 and 3). Yet it is exactly here that management of groups and institutes may prove effective, via the development of networking competencies in researchers, recruitment policies and drafting mentoring programs.

Open Access This article is distributed under the terms of the Creative Commons Attribution Noncommercial License which permits any noncommercial use, distribution, and reproduction in any medium, provided the original author(s) and source are credited.

\section{References}

Akerlind, G. S. (2005). Academic growth and development-How do university academics experience it? Higher Education, 50, 1-32.

Aram, J. D., \& Salipante, P. F. (2003). Bridging scholarship in management: Epistemological reflections. British Journal of Management, 14, 189-205.

Argyris, C. (1996). Unrecognized defenses of scholars: Impact on theory and research. Organization Science, 7, 79-87.

Baert, P., \& Shipman, A. (2005). University under siege? Trust and accountability in the contemporary academy. European Societies, 7, 157-185.

Bleiklie, I. (2005). Organizing higher education in a knowledge society. Higher Education, 49, 31-59.

Choi, B., \& Lee, H. (2002). Knowledge management strategy and its link to knowledge creation process. Expert Systems with Applications, 23, 173-187.

Cohen, L., Duberley, J., \& McAuley, J. (1999). Fuelling discovery or monitoring productivity: Research scientists' changing perceptions of management. Organization, 6, 473-497.

Cook, S. D. N., \& Brown, J. S. (1999). Bridging epistemologies: The generative dance between organizational knowledge and organizational knowing. Organization Science, 10, 381-400.

Creplet, F., Dupouet, O., Kern, F., Mehmanpazir, B., \& Munier, F. (2001). Consultants and experts in management consulting firms. Research Policy, 30, 1517-1535.

Crespo, M., \& Dridi, H. (2007). Intensification of university-industry relationships and its impact on academic research. Higher Education, 54, 61-84.

Dewett, T., \& Denisi, A. S. (2004). Exploring scholarly reputation: It's more than just productivity. Scientometrics, 60, 249-272.

Enders, J. (2005). Border crossings: Research training, knowledge dissemination and the transformation of academic work. Higher Education, 49, 119-133. 
Ernø-Kjølhede, E., Husted, K., Mønsted, M., \& Wenneberg, S. B. (2001). Managing university research in the triple helix. Science and Public Policy, 28, 49-55.

Gibbons, M., Limoges, C., Nowotny, H., Schwartzman, S., Scott, P., \& Trow, M. (1994). The new production of knowledge: The dynamics of science and research in contemporary societies. London: Sage.

Gottlieb, E. E., \& Keith, B. (1997). The academic research-teaching nexus in eight advanced-industrialized countries. Higher Education, 34, 397-419.

Gourlay, S. (2006). Conceptualizing knowledge creation: A critique of Nonaka's theory. Journal of Management Studies, 43, 1415-1436.

Grbich, C. (1998). The academic researcher: Socialisation in settings previously dominated by teaching. Higher Education, 36, 67-85.

Harvey, J., Pettigrew, A., \& Ferlie, E. (2002). The determinants of research group performance: Towards mode 2? Journal of Management Studies, 39, 747-774.

Hemmings, B. C., Rushbrook, P., \& Smith, E. (2007). Academics' views on publishing refereed works: A content analysis. Higher Education, 54, 307-332.

Henkel, M. (2005). Academic identity and autonomy in a changing policy environment. Higher Education, $49,155-176$.

Huff, A. S., \& Huff, J. O. (2001). Re-focusing the business school agenda. British Journal of Management, 12, S49-S54.

Jain, R. K., \& Triandis, H. C. (1997). Management of research and development organizations: Managing the unmanageable. New York: Wiley.

Johnson, W. H. A., \& Johnston, D. A. (2004). Organisational knowledge creating processes and the performance of university-industry collaborative R\&D projects. International Journal of Technology Management, 27, 93-114.

Knorr-Cetina, K. D. (1999). Epistemic cultures: How the sciences make knowledge. Cambridge: Harvard University Press.

Lambright, W. H., \& Teich, A. H. (1981). The organizational context of scientific research. In P. C. Nystrom \& W. H. Starbuck (Eds.), Handbook of organizational design (pp. 305-319). Oxford: Oxford University Press.

Landry, R., Traore, N., \& Godin, B. (1996). An econometric analysis of the effect of collaboration on academic research productivity. Higher Education, 32, 283-301.

Latour, B., Woolgar, S., \& Salk, J. (1979). Laboratory life: The social construction of scientific facts. Beverly Hills: Sage.

Majchrzak, A., Cooper, L. P., \& Neece, O. E. (2004). Knowledge reuse for innovation. Management Science, 50, 174-188.

Mohrman, S. A., Gibson, C. B., \& Mohrman, A. M. (2001). Doing research that is useful to practice: A model and empirical exploration. Academy of Management Journal, 44, 357-375.

Nonaka, I., \& Takeuchi, H. (1995). The knowledge-creating company: How Japanese companies create the dynamics of innovation. New York: Oxford University Press.

Nonaka, I., Toyama, R., \& Konno, N. (2000). SECI, ba and leadership: A unified model of dynamic knowledge creation. Long Range Planning, 33, 5-34.

Nowotny, H., Scott, P., \& Gibbons, M. (2003). 'Mode 2' revisited: The new production of knowledgeIntroduction. Minerva, 41, 179-194.

Patton, M. Q. (2001). Qualitative research \& evaluation methods. Thousand Oaks: Sage.

Polanyi, M. (1966). The Tacit dimension. New York: Anchor Day Books.

Rynes, S. L., Bartunek, J. M., \& Daft, R. L. (2001). Across the great divide: Knowledge creation and transfer between practitioners and academics. Academy of Management Journal, 44, 340-355.

Salisbury, M. (2001). An example of managing the knowledge creation process for a small work group. Management Learning, 32, 305-319.

Thomke, S. (1998). Managing experimentation in the design of new products. Management Science, 44, $743-762$.

Thompson, M. P. A., \& Walsham, G. (2004). Placing knowledge management in context. Journal of Management Studies, 41, 725-747.

Tsoukas, H. (2003). Do we really understand tacit knowledge? In M. Easterby-Smith \& M. A. Lyles (Eds.), The Blackwell handbook of organizational learning and knowledge management (pp. 410-427). Malden: Blackwell.

VSNU. (2003). Standard evaluation protocol 2003-2009 for public research organisations. VSNU-NWOKNAW, Utrecht. Amsterdam: The Hague.

Whitley, R. D. (2000). The intellectual and social organization of the sciences. Oxford: Oxford University Press. 